\title{
Renal Hemodynamic Responses to Hypoxemia during Development: Relationships to Circulating Vasoactive Substances
}

\author{
DOUGLAS N. WEISMANN AND JEAN E. ROBILLARD
}

Department of Pediatrics and the Cardiovascular Research Center, University of Iowa, Iowa City, Iowa 52242

\begin{abstract}
Chronically catheterized fetal lambs $(n=$ 11, gestational age 111-139 days) and neonatal lambs ( $n$ $=20$, postnatal age 4-30 days) were studied to explore during development the relationship of renal hemodynamic responses during hypoxemia to plasma epinephrine concentration (E), plasma norepinephrine concentration (NE), plasma arginine vasopressin concentration (AVP), and plasma renin activity (PRA). A low oxygen gas mixture $\left(11.1 \pm 0.1 \% O_{2}\right)$ was administered for $30 \mathrm{~min}$ to the pregnant ewe or neonatal lamb to induce hypoxemia with maintenance of normal arterial $\mathrm{pCO}_{2}$ and $\mathrm{pH}$. Arterial blood pressure was recorded continuously and renal blood flow (RBF) was determined by the radiolabeled microsphere technique. Moderate hypoxemia $\left(\mathrm{pO}_{2} 16 \pm 2\right.$ torr and $33 \pm 6$ torr in fetus and neonate, respectively) induced increases in $\mathrm{E}, \mathrm{NE}$ (measured by radioenzymatic assay), and AVP (measured by radioimmunoassay) in both fetus and neonate. PRA (measured by radioimmunoassay) also increased in response to hypoxemia in neonatal lambs. The change in mean arterial pressure with hypoxemia $(\triangle M A P)$ was significant in fetuses $(\triangle M A P 8 \pm 14 \%, p<0.05$ ) but not in lambs ( $\triangle$ MAP $1 \pm 10 \%, p>0.5)$. Similarly, the change in renal blood flow with hypoxemia $(\triangle \mathrm{RBF})$ was significant $(\triangle \mathrm{RBF}-51 \pm 24 \%, p<0.001)$ in fetuses but not in neonatal lambs $(\triangle \mathrm{RBF}-9 \pm 38 \%, p>0.1)$. These results reflected a change in renal vascular resistance with hypoxemia $(\triangle \mathbf{R V R})$ that was significant in fetal lambs $(\Delta$ RVR $169 \pm 168 \%, p<0.01)$ but not in neonatal lambs $(\triangle R V R 51 \pm 180 \%, p>0.2)$. The relationships of these renal hemodynamic responses to the measured vasoactive substances, and the influence of their interactions to produce these responses, were assessed by response surface regression analysis. The response surface regression model of responses to hypoxemia of $E(\Delta E), N E(\Delta N E)$, AVP ( $\triangle \mathrm{AVP}$ ), and PRA ( $\triangle \mathrm{PRA})$ to $\triangle \mathrm{MAP}$ and $\triangle R V R$ over the entire development period fit the data well (adjusted $\mathbf{R}^{2}$ 0.8427 and 0.8274 , respectively). $\Delta \mathrm{E}$ was the most predictive of the components for both $\triangle M A P$ and $\triangle R V R$ (F ratio 7.89 and 7.25 , respectively). Contour plots of the interaction of $\Delta E$ with postconceptional age and $\Delta N E$ demonstrated considerable age dependence of the relationship of $\triangle E$ and $\triangle N E$ to $\triangle M A P$ and $\triangle R V R$ during development. The results are consistent with the hypothesis that asynchronous maturation of vascular $\beta$-adrenergic (vasodilatory) and $\alpha$-adrenergic (vasoconstrictor) effector mechanisms occurs throughout the fetal/neonatal period. (Pediatr Res 23: 155-162, 1988)
\end{abstract}

Received February 12, 1987; accepted September 25, 1987

Correspondence and reprint requests Dr. Douglas N. Weismann, Department of Pediatrics, University of lowa Hospitals, Iowa City, IA 52242.

Supported in part by United States Public Health Service Grants AM-32958, DK-38302, HL-14388, HD-20576, and DK-32958. D.N.W. is the recipient of NIADDK Research Career Development Award AM-01399.

\author{
Abbreviations \\ E, plasma epinephrine concentration \\ NE, plasma norepinephrine concentration \\ AVP, plasma arginine vasopressin concentration \\ PRA, plasma renin activity \\ MAP, mean arterial pressure \\ RBF, renal blood flow \\ RVR, renal vascular resistance \\ $\Delta \mathbf{E}$, change in $\mathbf{E}$ with hypoxemia \\ $\Delta \mathrm{NE}$, change in NE with hypoxemia \\ $\triangle \mathrm{AVP}$, change in AVP with hypoxemia \\ $\triangle$ PRA, change in PRA with hypoxemia \\ $\triangle$ MAP, change in MAP with hypoxemia \\ $\triangle \mathrm{RBF}$, change in RBF with hypoxemia \\ $\triangle R V R$, change in RVR with hypoxemia
}

Perinatal hypoxemia continues to be a major problem encountered in obstetric/neonatology practice (1). Major hemodynamic adjustments occur in response to perinatal asphyxia or hypoxemia, including response of RBF and RVR (2-9). Numerous circulating vasoactive mediators appear in increased concentration in blood in response to perinatal hypoxemia, including $\mathrm{E}$ (10-16), NE (10-16), AVP (9, 12, 15-20), and PRA $(9,12,15$, 21). Furthermore, previous work has demonstrated hemodynamic and renal responses to hypoxemia that appear to be developmental age dependent $(9,22,23)$.

The roles of circulating mediators in fetal/neonatal responses to hypoxemia remain unclear. The mechanism(s) of responses to hypoxemia, as studied in adult animals, appears to be complex, involving systemic sympathetic reflexes and local vascular actions as well as responses to circulating vasoactive mediators (18, 24-26). Due to the complex nature of this condition, the role of individual circulating mediators is not likely to be substantiated by study of isolated infusions of these mediators or specific inhibitors. Therefore, the relationships of circulating vasoactive mediators to the systemic arterial pressure and renovascular responses to hypoxemia in the developing lamb were examined by the technique of response surface regression analysis that allows examination of interactions among variables as well as quantitation of their main effects $(26,27)$. The responses of $E$, NE, AVP, and PRA were measured in hypoxemic, chronically catheterized fetal and neonatal lambs and analyzed in terms of their relationship to responses of MAP, RBF, and RVR during development.

\section{METHODS}

Mixed-breed Dorset Suffolk lambs and pregnant ewes were obtained from a local source. Gestational age of fetuses was based on the induced ovulation technique (28). 
Surgical procedures. Pregnant ewes were fasted for $48 \mathrm{~h}$ prior to surgery. Induction of anesthesia of the ewe and fetal surgical procedures were performed as described previously (12, 29-31). Anesthesia and surgical procedures in neonatal lambs were also performed as described previously $(9,15)$. Briefly, in the fetus, catheters were placed in one femoral artery and a femoral vein with catheter tips located in the distal abdominal aorta and inferior vena cava, respectively. An additional catheter was placed in the amniotic cavity for recording of intrauterine pressure. In the neonate, chronic catheters were placed in both femoral arteries and a femoral vein. Catheter tips were located in the left ventricular cardiac chamber, distal abdominal aorta, and distal vena cava, respectively. Recovery from surgical procedures of 6 days for fetal lambs and 3 days for neonatal lambs was provided prior to performance of the experimental protocol.

Experimental protocol. Fetal lambs $(n=11)$ of $111-139$ days (mean $125 \pm 12$ days) gestational age (term 145 days) and neonatal lambs $(n=20) 4-30$ days (mean $9 \pm 6$ days) postnatal age were studied. Each experimental animal was studied only once. These chronically catheterized animals were studied while in a standing posture in a canvas harness (lambs) or a small cart (ewes with in utero fetus). Arterial blood pressure was recorded continuously on a Beckman R611 dynograph by means of a pressure transducer (Statham) connected to the femoral arterial catheter with its tip in the distal abdominal aorta. Arterial blood samples were collected for determinations of $\mathrm{pH}, \mathrm{pCO}_{2}, \mathrm{pO}_{2}, \mathrm{E}$, NE, AVP, and PRA. Withdrawn blood was immediately replaced by maternal blood in fetal experiments or plasma protein fraction (Plasmanate, Cutter Laboratories) in neonatal experiments. Subsequently, microspheres ( $15 \pm 3 \mu \mathrm{m}$ diameter, $3 \mathrm{M}$ Company) labeled with a single radioactive isotope $\left({ }^{141} \mathrm{Ce},{ }^{85} \mathrm{Sr},{ }^{46} \mathrm{Sc}\right.$, or ${ }^{95} \mathrm{Nb}$ ) were suspended in $3 \mathrm{ml}$ of $0.9 \%$ saline solution and agitated thoroughly. In fetal experiments approximately $4.0 \times 10^{6}$ microspheres were injected into the fetal femoral vein catheter over a 30 -s period. In neonatal experiments approximately $1.5 \times 10^{6}$ microspheres were injected into the left ventricular catheter over a 30-s period. In all experiments the microspheres injection was followed by a $3-\mathrm{ml}$ bolus flush of $0.9 \%$ saline solution. An independent lower body reference sample was obtained by withdrawal of blood (Harvard infusion/withdrawal pump) through a femoral arterial catheter at a rate of $2.91 \mathrm{ml} / \mathrm{min}$ (fetuses) or $1.94 \mathrm{ml} / \mathrm{min}$ (neonates) for a period of $3 \mathrm{~min}$ starting approximately $20 \mathrm{~s}$ before the microspheres injection (32).

After the microspheres injection, systemic hypoxemia was produced by directing an $11.1 \pm 0.01 \%$ oxygen in nitrogen gas mixture (Air Products Co.) into a clear plastic bag that was placed over the head of the ewe or neonatal lamb, as described previously $(9,12,15)$. During the first few minutes of administration of the oxygen deficient inhaled gas mixture, the gas mixture flow rate was adjusted according to the blood gas measurements in order to maintain $\mathrm{pH}$ and $\mathrm{pCO}_{2}$ values within the normal range. Thirty min after initiation of the hypoxic gas mixture administration, arterial blood was sampled for $\mathrm{pH}$, $\mathrm{pCO}_{2}, \mathrm{pO}_{2}, \mathrm{E}, \mathrm{NE}, \mathrm{AVP}$, and PRA. A second injection of radioactive microspheres labeled with a different isotope was then performed as previously described. The fetus or neonate was subsequently killed by bolus intravenous administration of a lethal dose of sodium pentobarbital (Somlethal, Med-Tech, Inc.). The kidneys were immediately harvested, weighed, cut into sagittal sections of approximately $1 \mathrm{~g}$, and placed in counting vials.

Analytical procedures. Arterial blood $\mathrm{pH}, \mathrm{pO}_{2}$, and $\mathrm{pCO}_{2}$ were determined by a Radiometer $\mathrm{pH} /$ blood gas analyzer. Radiolabeled microsphere $\left({ }^{85} \mathrm{Sr},{ }^{141} \mathrm{Ce},{ }^{46} \mathrm{Sc},{ }^{95} \mathrm{Nb}\right)$ content of blood and tissue was determined by counting in a $\gamma$-spectrometer (Beckman 300) with isotope separation by standard methods (33). Samples of blood for determination of PRA were collected in chilled tubes containing EDTA, placed on ice, and centrifuged at $4^{\circ} \mathrm{C}$ within $20 \mathrm{~min}$. Plasma renin activity was determined by radioimmunoassay using the method of Haber et al. (34) as modified by Oparil
(35). Plasma vasopressin was extracted using the bentonite extraction and measured by radioimmunoassay procedures of Skowsky et al. (36). Vasopressin assays were performed in the Core Laboratory of the University of Iowa Cardiovascular Center. Arterial blood epinephrine and norepinephrine content were determined by radioenzymatic assay (Cat-a-Kit, Upjohn Co.) as described by Peuler and Johnson (37).

Calculations and data analysis. RBF was determined according to the formula: $\mathrm{RBF}(\mathrm{ml} / \mathrm{min})=$ total kidney radioactivity (counts/min) $\times$ reference flow rate from the femoral artery $(\mathrm{ml} /$ min) $\div$ total radioactivity of reference blood sample in counts/ min. RVR was calculated according to the formula: RVR (mm $\mathrm{Hg} / \mathrm{ml} / \mathrm{min})=$ mean arterial pressure $(\mathrm{mm} \mathrm{Hg}) \div \mathrm{RBF}(\mathrm{ml} /$ $\mathrm{min}$ ). Comparisons of values among the age groups were performed by analysis of variance (38). Response surface regression analysis was used to characterize the relationship of dependent and independent variables. Two animals had missing data so that 29 animals contributed to the response surface regression analysis. $\triangle \mathrm{MAP}, \triangle \mathrm{RBF}$, and $\triangle \mathrm{RVR}$ were regressed on changes in arterial $\triangle \mathrm{E}, \triangle \mathrm{NE}, \triangle \mathrm{AVP}$ and $\triangle \mathrm{PRA}$. The response surface of $\triangle \mathrm{MAP}, \triangle \mathrm{RBF}$, or $\triangle \mathrm{RVR}$ was individually plotted with respect to two of the independent variables, and factored according to postconceptional age. For the individual analyses, the remaining independent variables were controlled by mathematically placing them at zero change (26). A $p$ value of less than 0.05 was required for a difference to be declared significant.

\section{RESULTS}

Arterial blood values. Fetal and neonatal lambs developed significant hypoxemia without significant changes in arterial $\mathrm{pH}$ (Table 1) when hypoxic gas mixture was administered to the maternal ewe or neonatal lamb, respectively. Although arterial $\mathrm{pCO}_{2}$ decreased significantly in response to hypoxemia in fetal lambs, the change was very small. Significant increases in arterial $\mathrm{NE}$ (from $0.438 \pm 0.237$ to $2.54 \pm 1.87 \mathrm{ng} / \mathrm{ml}, p<0.01$ ), E (from $0.017 \pm 0.014$ to $1.02 \pm 1.80 \mathrm{ng} / \mathrm{ml}, p<0.01$ ), and AVP (from $2.43 \pm 1.08$ to $50.70 \pm 56.70 \mu \mathrm{U} / \mathrm{ml}, p<0.01$ ) occurred in response to hypoxemia in fetal lambs. Arterial PRA did not change significantly (from $7.30 \pm 11.20$ to $9.74 \pm 17.50 \mathrm{ng} / \mathrm{ml}$. min, $p>0.2)$ in response to hypoxemia in fetal lambs. This small change in PRA in fetal lambs in response to hypoxemia ( $\triangle \mathrm{PRA})$ is due primarily to the very small response in the very young $(<120$ day) fetuses ( $\triangle \mathrm{PRA} 0.13 \pm 0.98 \mathrm{ng} / \mathrm{ml} \cdot \mathrm{min})$ as opposed to the older ( $>130$ day) fetuses $(\triangle P R A 4.5 \pm 9.3 \mathrm{ng} /$ $\mathrm{ml} \cdot \mathrm{min}$ ). Similarly, significant increases in NE (from $0.428 \pm$ 0.265 to $3.63 \pm 7.15 \mathrm{ng} / \mathrm{ml}, p<0.01$ ), $\mathrm{E}$ (from $0.126 \pm 0.108$ to $2.99 \pm 10.40 \mathrm{ng} / \mathrm{ml}, p<0.01$ ), and AVP (from $3.75 \pm 5.48$ to $25.60 \pm 43.20 \mu \mathrm{U} / \mathrm{ml}, p<0.01)$ in response to hypoxemia were seen in neonatal lambs. In contrast to the response in the fetus, PRA increased significantly (from $13.10 \pm 10.20$ to $23.70 \pm$ $23.90 \mathrm{ng} / \mathrm{ml} \cdot \min , p<0.01$ ) in response to hypoxemia in neonatal lambs. Changes in NE $(\Delta N E), E(\Delta E)$, AVP $(\triangle A V P)$, and PRA ( $\triangle$ PRA) in response to hypoxemia in fetal and neonatal lambs are presented in Figure 1. There were no significant differences $(p>0.5)$ between fetal and neonatal lambs. $\Delta$ AVP, on the other hand, was significantly smaller and $\triangle P R A$ was significantly greater in neonatal lambs.

Renal hemodynamics. Arterial Blood Pressure. MAP increased slightly, but significantly, in response to hypoxemia in fetal lambs (from $46 \pm 5$ to $50 \pm 11 \mathrm{~mm} \mathrm{Hg}, p<0.05$ ) (Fig. 2). MAP was unchanged in response to hypoxemia in neonatal lambs (from $78 \pm 10$ to $79 \pm 13 \mathrm{~mm} \mathrm{Hg}, p>0.5$ ) (Fig. 2). To illustrate the distribution of the animals in terms of postconceptional age and their respective change in MAP with hypoxemia $(\triangle \mathrm{MAP}), \triangle \mathrm{MAP}$ versus postconceptional age is plotted in Figure 3. To determine the relationship of MAP responses to responses of $E$, NE, AVP, and PRA during hypoxemia, and the interactions of these variables in producing the MAP response, response surface regression analysis was performed. $\triangle \mathrm{MAP}$ was regressed on postconcep- 
tional age, $\triangle \mathrm{NE}, \triangle \mathrm{E}, \triangle \mathrm{AVP}$, and $\triangle \mathrm{PRA}$ (Table 2). This model was shown to explain greater than $84 \%$ of the variability of the data (adj. $R^{2}=0.8427$ ). Analysis of the contribution of each variable individually to the overall $\triangle \mathrm{MAP}$ effect demonstrates that only the E component is significant (Table 2). The interrelationships of the variables were further analyzed and threedimensional contour plots of predicted $\triangle \mathrm{MAP}$ against two of the independent variables were performed in selected cases for illustrative purposes. In the analysis, independent variables not being directly considered were controlled by setting them at zero change. See Appendix for demonstration of mechanics of plotting individual points on the three-dimensional response surface contours.

Of the variables examined, the interaction of postconceptional age with $\triangle \mathrm{NE}$ ( $\mathrm{T}$ ratio $2.95, p<0.019$ ), $\Delta \mathrm{E}$ ( $\mathrm{T}$ ratio $-2.61, p<$ 0.032 ), $\Delta$ AVP ( $\mathrm{T}$ ratio $-2.53, p<0.035$ ), and $\triangle \mathrm{PRA}$ ( $\mathrm{T}$ ratio $-2.55, p<0.035$ ), as factors in the mean arterial pressure response to hypoxemia, were significant. The contour plot of predicted $\triangle \mathrm{MAP}$ in relation to $\triangle \mathrm{NE}$ and postconceptional age is shown in Figure $4 A$. This plot demonstrates that a given $\triangle \mathrm{NE}$ during hypoxemia is associated with a falling predicted $\triangle \mathrm{MAP}$ during the early postconceptional (fetal) period until just prior to birth (145 days postconceptional age). Thereafter, the same $\triangle \mathrm{NE}$ in the postnatal lamb is associated with a progressively rising predicted $\triangle \mathrm{MAP}$ as postnatal age increases. In contrast, the contour plot of predicted $\triangle \mathrm{MAP}$ in relation to $\triangle \mathrm{E}$ and postconceptional age by this analysis (Fig. $4 B$ ) demonstrates a predicted $\triangle$ MAP pattern that is the reciprocal of the $\triangle N E$ postconceptional age pattern. A given $\Delta \mathrm{E}$ during hypoxemia is associated with a rising predicted $\triangle$ MAP during the early postconceptional (fetal) period until just after birth. Thereafter, the same $\Delta \mathrm{E}$ in the postnatal lamb is associated with a progressively falling predicted $\triangle \mathrm{MAP}$ as postnatal age increases (Fig. $4 B$ ). For example, at $\Delta \mathrm{E}$ of $1500 \mathrm{pg} / \mathrm{ml}$, a response near the average for lambs in these experiments, a rising $\triangle \mathrm{MAP}$ is predicted until approximately the time of birth, after which a falling $\triangle \mathrm{MAP}$ is the predicted response. Because $\triangle \mathrm{NE}$ and $\Delta \mathrm{E}$ have significant but opposing relationships with postconceptional age in respect to $\triangle \mathrm{MAP}$, the interactions of the three independent variables may be important in the overall $\triangle \mathrm{MAP}$ response to hypoxemia during development. Therefore, analysis of the inter-

Table 1. Arterial blood $p H$ and gas values (mean $\pm S D$ )

\begin{tabular}{lccccc}
\hline & \multicolumn{2}{c}{ Fetal lambs $(n=11)$} & & \multicolumn{2}{c}{ Neonatal lambs $(n=20)$} \\
\cline { 2 - 3 } \cline { 5 - 6 } Variable & Baseline & Hypoxemia & & Baseline & Hypoxemia \\
\hline $\mathrm{pO}_{2}$ (torr) & $27 \pm 3$ & $16 \pm 2^{*}$ & & $90 \pm 10$ & $33 \pm 6^{*}$ \\
$\mathrm{pH}$ & $7.38 \pm 0.03$ & $7.38 \pm 0.03$ & & $7.40 \pm 0.09$ & $7.39 \pm 0.16$ \\
$\mathrm{pCO}_{2}$ (torr) & $42 \pm 3$ & $38 \pm 2^{*}$ & & $34 \pm 4$ & $33 \pm 7$ \\
\hline
\end{tabular}

* Comparison of hypoxemia to baseline value is significant, $p<0.05$. actions of $\Delta \mathrm{E}, \Delta \mathrm{NE}$, and postconceptional age with $\triangle \mathrm{MAP}$ were performed and the response surface plots for predicted $\triangle \mathrm{MAP}$ in relation to $\triangle \mathrm{E}$ and $\triangle \mathrm{NE}$ at representative developmental ages are depicted in Figure 5. As shown in Figure $5 \mathrm{~A}$, at a postconceptional age of 125 days (i.e., early in the 3rd trimester of fetal development), lower values of $\triangle \mathrm{NE}$ are associated with progressively rising predicted $\triangle \mathrm{MAP}$ as $\triangle \mathrm{E}$ increases until a plateau is reached at a $\Delta \mathrm{E}$ of approximately $3000 \mathrm{pg} / \mathrm{ml}$. Thereafter, further rises in $\triangle \mathrm{E}$ are associated with lesser rises in predicted $\triangle \mathrm{MAP}$. At higher values of $\triangle \mathrm{NE}$ at this developmental age, a similar pattern is seen except that increasing $\Delta E$ is associated with a lower maximum predicted $\triangle \mathrm{MAP}$ response. Also, at levels of $\Delta \mathrm{E}$ beyond the maximum predicted $\triangle \mathrm{MAP}$ response, the rise in predicted $\triangle \mathrm{MAP}$ with increasing $\triangle \mathrm{E}$ gradually decreases until, at very high levels of $\Delta \mathrm{E}$, predicted $\triangle \mathrm{MAP}$ becomes increasingly negative as $\Delta \mathrm{E}$ increases.

The pattern of predicted $\triangle \mathrm{MAP}$ response evolves to one at

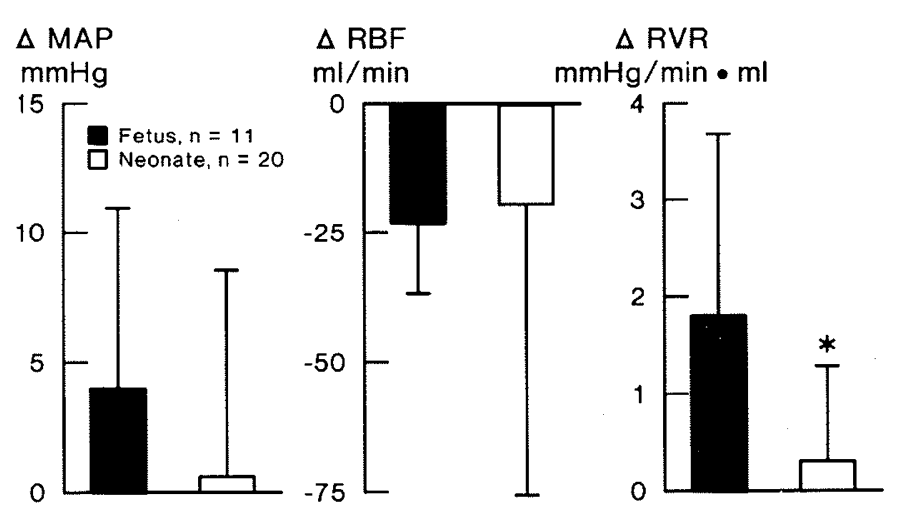

Fig. 2. $\triangle \mathrm{MAP}, \triangle \mathrm{RBF}$, and $\triangle \mathrm{RVR}$ in response to hypoxemia in sheep fetus and neonate. Values are mean $\pm \mathrm{SD}$. ${ }^{*}$ Value in neonate is significantly different from fetus, $p<0.01$.

Table 2. Relationship of change in MAP with hypoxemia to measured variables by response surface regression analysis*

\begin{tabular}{lrrcc}
\hline \multicolumn{1}{c}{ Factor } & df & ratio & $p$ & adj. $\mathrm{R}^{2}$ \\
\hline Total regression & 20 & 8.47 & 0.0021 & 0.8427 \\
Age & 6 & 1.52 & 0.2852 & \\
$\Delta \mathrm{NE}$ & 6 & 2.61 & 0.1046 & \\
$\Delta \mathrm{E}$ & 6 & 7.89 & 0.0051 & \\
$\Delta$ AVP & 6 & 2.15 & 0.1562 & \\
$\Delta$ PRA & 6 & 3.05 & 0.0740 & \\
\hline
\end{tabular}

* All changes are in response to hypoxemia.
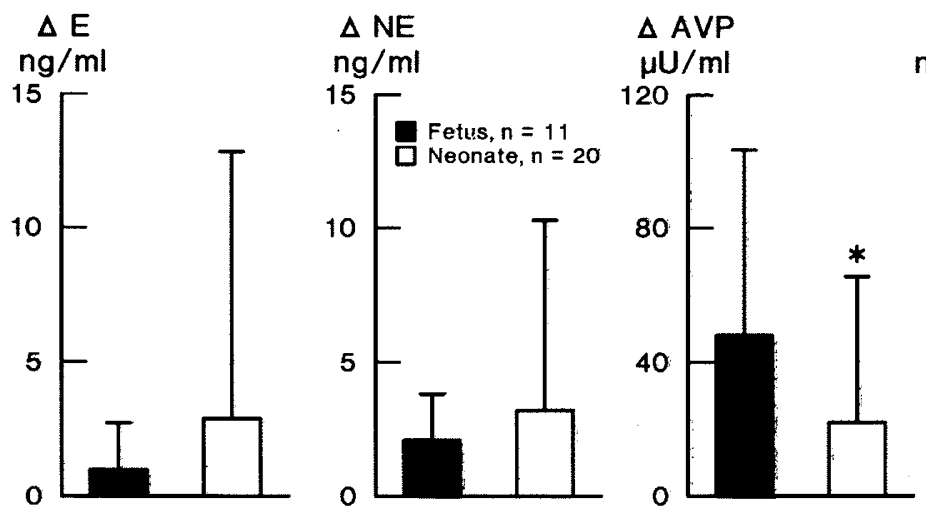

$\triangle$ PRA

$\mathrm{ng} / \mathrm{ml} \cdot \min$

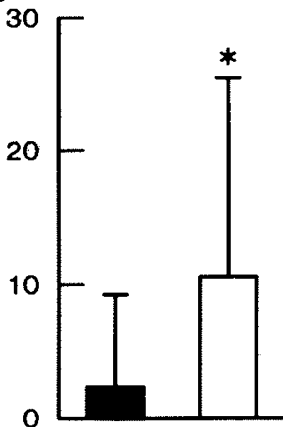

Fig. 1. $\triangle \mathrm{E}, \triangle \mathrm{NE}, \triangle \mathrm{AVP}$, and $\triangle \mathrm{PRA}$ in response to hypoxemia in sheep fetus and neonate. Values are mean $\pm \mathrm{SD}$. ${ }^{*} \mathrm{Value}$ in neonate is significantly different from fetus, $p<0.02$. 


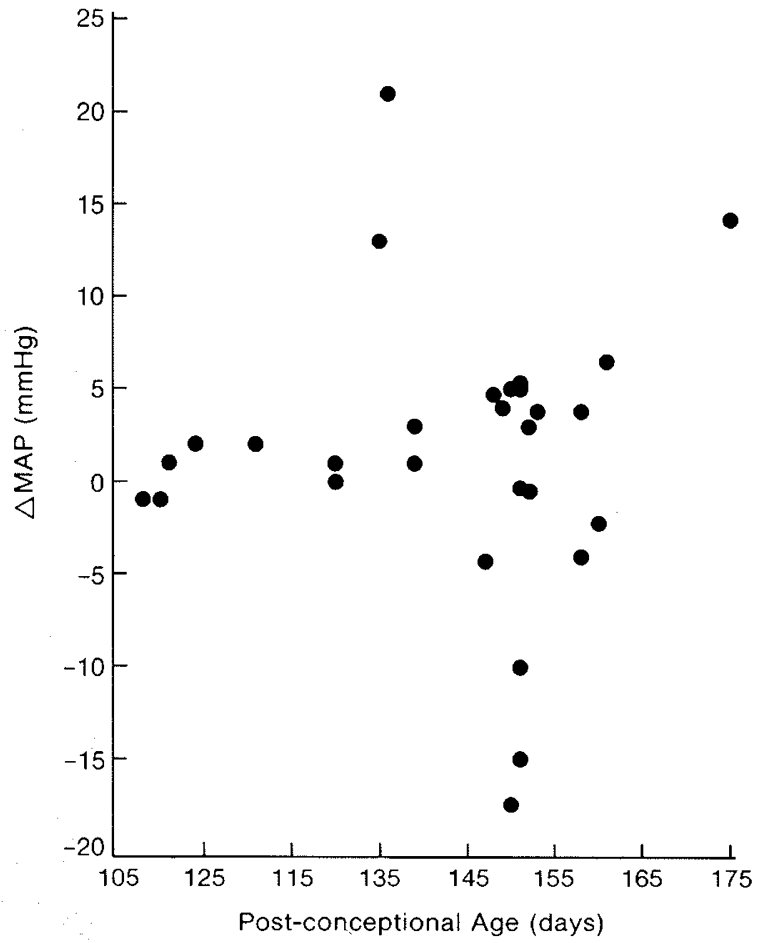

Fig. 3. Relationship of $\triangle M A P$ in response to hypoxemia to postconceptional age.
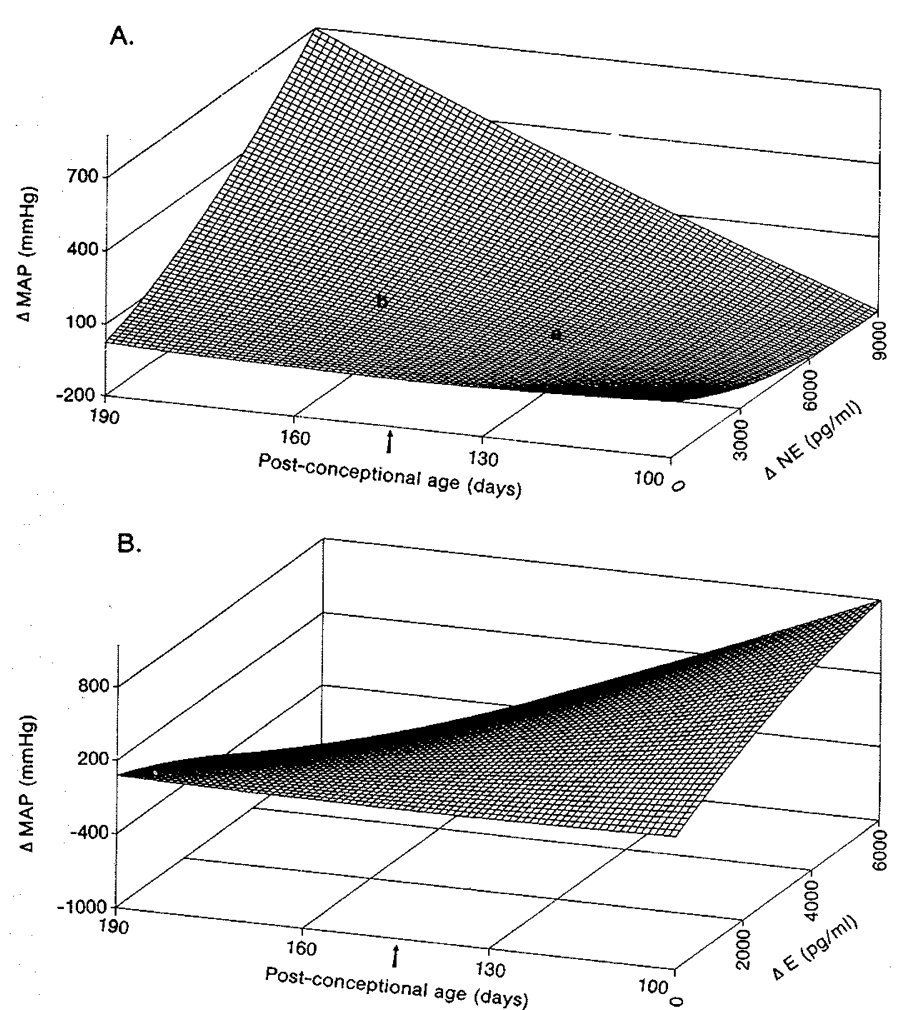

Fig. 4. Contour plots of predicted $\triangle \mathrm{MAP}$ in relation to postconceptional age and $A$ change in $\triangle \mathrm{NE}$ or $B$ change in $\Delta \mathrm{E}$ in response to hypoxemia. Illustrative points are plotted on $A$ for a given $\triangle$ NE response of $3000 \mathrm{pg} / \mathrm{ml}: a$ signifies a predicted $\triangle \mathrm{MAP}$ of $0 \mathrm{~mm} \mathrm{Hg}$ at 130 days post-conceptional age given the $\triangle \mathrm{NE}$ of $3000 \mathrm{pg} / \mathrm{ml} . b$ signifies a predicted $\triangle \mathrm{MAP}$ of $100 \mathrm{~mm} \mathrm{Hg}$ at 160 days postconceptional age given the identical $\triangle N E$ of $3000 \mathrm{pg} / \mathrm{ml}$. See "Appendix" for mechanics of plotting individual points on a three-dimensional response surface contour plot. The arrow at postconceptional age 145 days signifies birth.
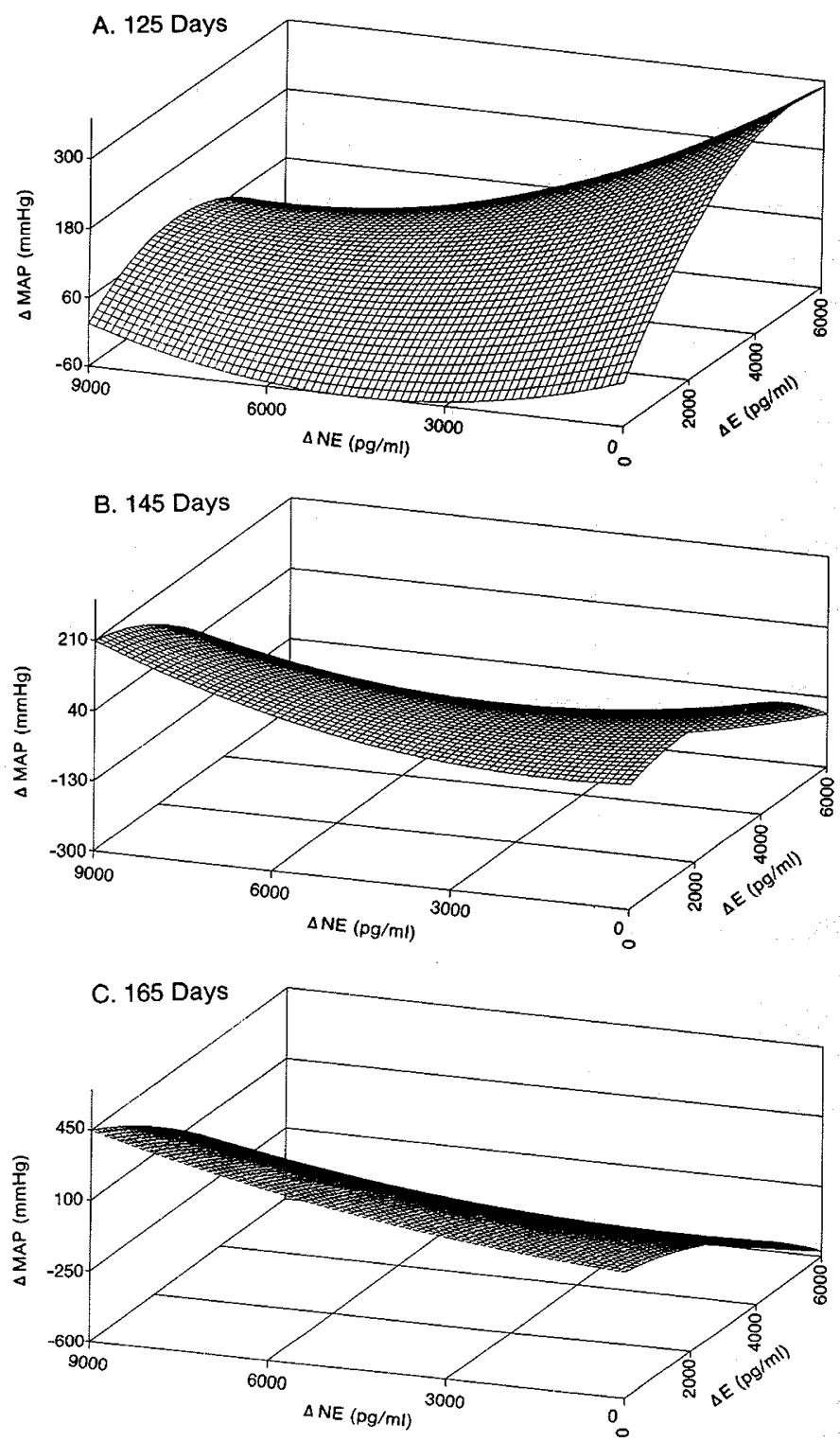

Fig. 5. Contour plots of predicted $\triangle \mathrm{MAP}$ in relation to $\triangle \mathrm{NE}$ and $\triangle \mathrm{E}$, at representative postconceptional ages. $A, 125$ days postconceptional age; $B, 145$ days postconceptional age; and $C, 165$ days postconceptional age.

Table 3. Relationship of change in $R B F$ with hypoxemia to measured variables by response surface regression analysis*

\begin{tabular}{lrrcc}
\hline \multicolumn{1}{c}{ Factor } & df & ratio & $p$ & Adj. $\mathrm{R}^{2}$ \\
\hline Total regression & 20 & 1.24 & 0.3954 & 0.1462 \\
Age & 6 & 0.84 & 0.5712 & \\
$\Delta \mathrm{NE}$ & 6 & 0.58 & 0.7392 & \\
$\Delta \mathrm{E}$ & 6 & 1.01 & 0.4785 & \\
$\Delta \mathrm{AVP}$ & 6 & 0.93 & 0.5193 & \\
$\Delta$ PRA & 6 & 0.67 & 0.6761 & \\
\hline
\end{tabular}

* All changes are in response to hypoxemia.

birth (postconceptional age 145 days) where progressively greater $\Delta \mathrm{NE}$ values, irrespective of $\Delta \mathrm{E}$, are associated with progressively greater predicted $\triangle \mathrm{MAP}$ at a steeper incline relative to that seen at 125 days postconceptional age (Fig. $5 B$ ). In addition, at progressively increasing values of $\Delta \mathrm{E}$ at a given $\triangle \mathrm{NE}$, predicted $\Delta$ MAP rises less steeply than it does at 125 days postconceptional 
age, plateaus, and then is associated with a steeper descent as $\Delta \mathrm{E}$ increases further relative to that seen at 125 days postconceptional age. This pattern continues to evolve until at postconceptional age of 165 days (20-day-old neonatal lamb), the incline of predicted $\triangle \mathrm{MAP}$ with increasing $\triangle \mathrm{NE}$ at a given $\triangle \mathrm{E}$ is similar to that at 145 days, but there is little or no rise of predicted $\triangle \mathrm{MAP}$ as $\triangle \mathrm{E}$ increases. Rather, predicted $\triangle \mathrm{MAP}$ progressively falls with increasing $\Delta \mathrm{E}$ at any given $\triangle \mathrm{NE}$, resulting in large negative values of $\triangle \mathrm{MAP}$ at high levels of $\Delta \mathrm{E}$ at that postconceptional age (Fig. $5 C$ ). Thus, the contour appears to rotate on its horizontal (Y) axis toward more negative responses of $\triangle \mathrm{MAP}$ as postconceptional age increases.

$R B F$. RBF decreased significantly in response to hypoxemia in fetal lambs (from $43.0 \pm 13.6$ to $20.2 \pm 10.5 \mathrm{ml} / \mathrm{min}, p<$ 0.001 ). The $\triangle \mathrm{RBF}$ in neonatal lambs (from $166 \pm 87$ to $146 \pm$ $84 \mathrm{ml} / \mathrm{min})$, however, was not significant $(p>0.1) . \Delta \mathrm{RBF}$ in fetal and neonatal lambs is depicted in Figure 2. There was no significant difference $(p>0.1)$ of $\triangle \mathrm{RBF}$ in comparisons of fetal to neonatal lambs. The individual relationships of $\triangle \mathrm{RBF}$ to age, $\triangle \mathrm{NE}, \triangle \mathrm{E}, \triangle \mathrm{AVP}$, and $\triangle \mathrm{PRA}$ were examined by response surface regression analysis (Table 3 ). None of the independent variables

Table 4. Relationship of change in RVR with hypoxemia to measured variables by response surface regression analysis*

\begin{tabular}{lrrcc}
\hline \multicolumn{1}{c}{ Factor } & df & ratio & $p$ & Adj. $\mathbf{R}^{2}$ \\
\hline Total regression & 20 & 7.71 & 0.0029 & 0.8274 \\
Age & 6 & 3.23 & 0.0644 & \\
$\Delta \mathrm{NE}$ & 6 & 6.20 & 0.0109 & \\
$\Delta \mathrm{E}$ & 6 & 7.35 & 0.0064 & \\
$\Delta$ AVP & 6 & 3.02 & 0.0754 & \\
$\Delta$ PRA & 6 & 1.51 & 0.2865 & \\
\hline
\end{tabular}

* All changes are in response to hypoxemia.
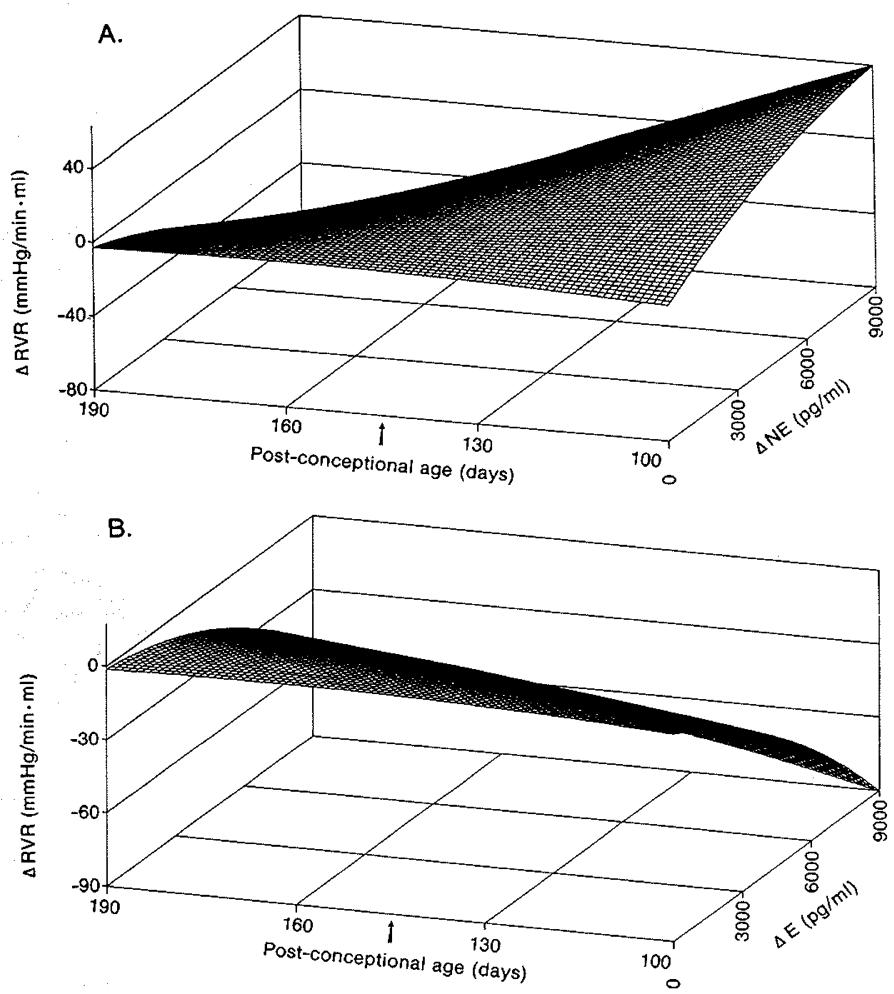

Fig. 6. Contour plots of predicted change in $\triangle R V R$ in relation to postconceptional age and $A \Delta \mathrm{NE}$ or $B \Delta \mathrm{E}$. Arrow at postconceptional age 145 days signifies birth.
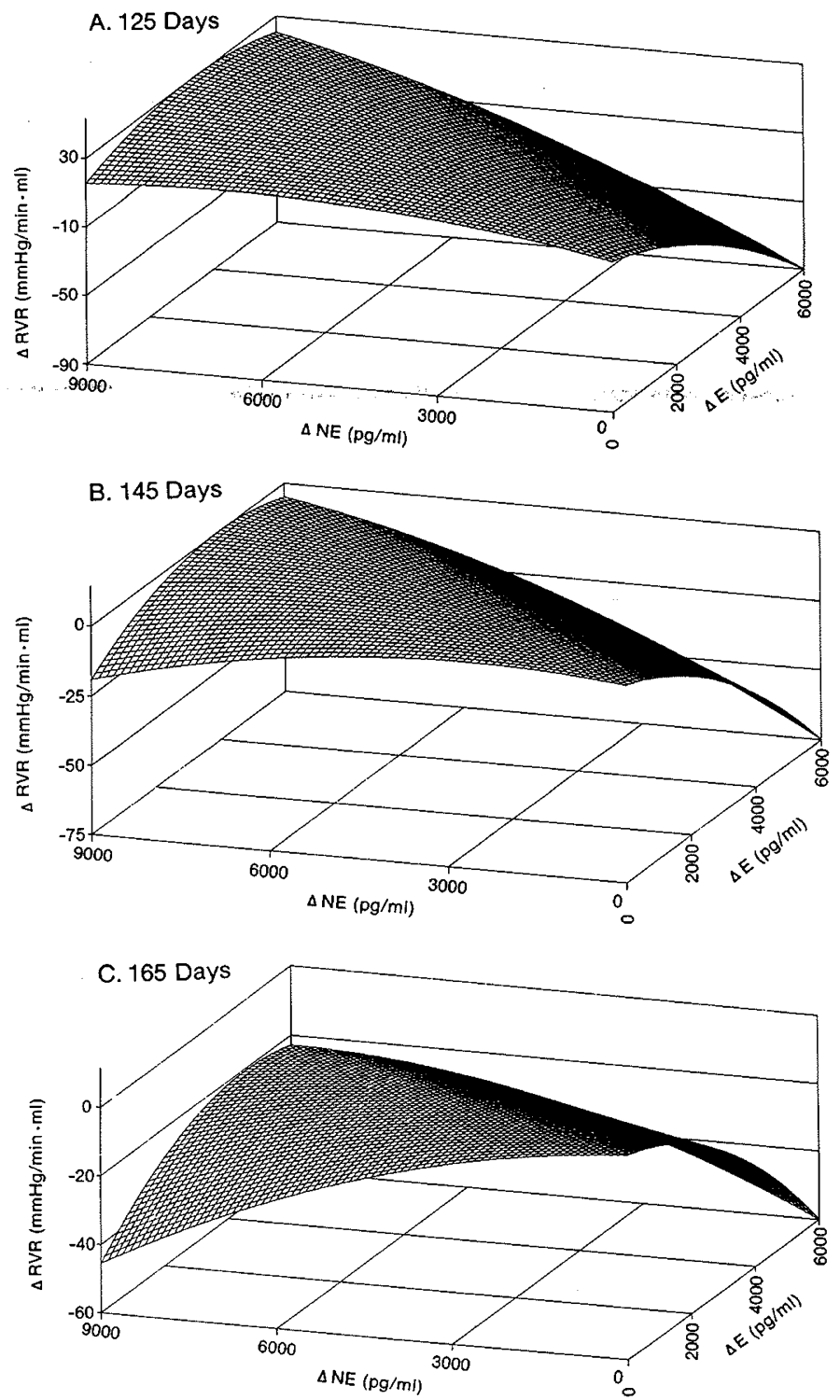

Fig. 7. Contour plots of predicted $\triangle \mathrm{RVR}$ in relation to $\triangle \mathrm{NE}$ and $\triangle \mathrm{E}$ at representative postconceptional ages. $A, 125$ days postconceptional age; $B, 145$ days postconceptional age; and $C, 165$ days postconceptional age.

measured bore a significant relationship to $\triangle \mathrm{RBF}$ and the overall model did not explain the variability well (adjusted $R^{2}=0.1462$ ).

$R V R$. RVR increased significantly in response to hypoxemia in fetal lambs (from $1.105 \pm 0.290$ to $3.000 \pm 1.870 \mathrm{~mm} \mathrm{Hg}$ / $\mathrm{ml} \cdot \mathrm{min}, p<0.01)$. RVR did not change significantly in response to hypoxemia in neonatal lambs (from $0.589 \pm 0.281$ to 0.910 $\pm 1.140 \mathrm{~mm} \mathrm{Hg} / \mathrm{ml} \cdot \mathrm{min}, p>0.2)$. The change in RVR with hypoxemia $(\triangle \mathrm{RVR})$ was significantly smaller in neonatal relative to fetal lambs (Fig. 2). Analysis of the relationship of $\triangle R V R$ to postnatal age, $\Delta \mathrm{E}, \Delta \mathrm{NE}, \Delta \mathrm{AVP}$, and $\triangle \mathrm{PRA}$ by response surface regression analysis is summarized in Table 4 . This model explained approximately $83 \%$ of the variability of the data (adj. $R^{2}$ $=0.8274) . \Delta \mathrm{NE}$ and $\Delta \mathrm{E}$ each contributed significantly to the overall $\triangle R V R$ response, whereas the contribution of $\triangle A V P$ and postconceptional age were of borderline significance (Table 4). $\triangle$ PRA appeared not to contribute significantly to the overall $\triangle$ RVR effect.

To further analyze these relationships, the interrelationships of two of the independent variables with $\triangle R V R$ were examined, and selected three-dimensional contour plots were performed for 
illustrative purposes, as in the $\triangle \mathrm{MAP}$ analysis. Independent variables not being directly considered were controlled by setting them at zero change, as seen previously.

The only variables with significant interaction in the $\triangle \mathrm{RVR}$ response by this analysis were $\Delta \mathrm{NE}$ versus postconceptional age ( $\mathrm{T}$ ratio $-2.36, p<0.046$ ) and $\Delta \mathrm{E}$ versus postconceptional age (T ratio $2.87, p<0.021$ ). The contour plot of predicted $\triangle \mathrm{RVR}$ in relation to $\triangle \mathrm{NE}$ and postconceptional age demonstrates that any given $\triangle \mathrm{NE}$ is associated with a rising predicted $\triangle \mathrm{RVR}$ at early postconceptional (fetal) age (Fig. 6A). With increasing postconceptional age a transitional point is encountered at just after the time of birth (postconceptional age of 145 days), with a given $\triangle \mathrm{NE}$ now being associated with a declining predicted $\triangle R V R$ as postconceptional age increases. In contrast, the analysis of the relation of $\triangle \mathrm{RVR}$ to $\Delta \mathrm{E}$ and postconceptional age (Fig. $6 B$ ) showed that predicted $\triangle \mathrm{RVR}$ is negative at all levels of $\Delta \mathrm{E}$ at each postconceptional age, but becomes decreasingly negative with increasing postconceptional age. Thus, the independent interactions of $\Delta \mathrm{E}$ and $\Delta \mathrm{NE}$ with postconceptional age in relation to $\Delta \mathrm{RVR}$ oppose one another when analyzed individually.

To further understand these relationships, further analysis of the interaction of these three variables (i.e. $\Delta \mathrm{NE}, \Delta \mathrm{E}$, and postconceptional age) in relation to $\triangle \mathrm{RVR}$ was performed and illustrative three-dimensional contour plots are presented (Fig. $7)$. At the earliest postconceptional ages (e.g. 125 days) a given $\triangle \mathrm{NE}$ is associated with rising predicted $\triangle \mathrm{RVR}$ with increasing $\Delta \mathrm{E}$ at high values of $\Delta \mathrm{NE}$, but progressively decreasing $\triangle \mathrm{RVR}$ at low values of $\triangle \mathrm{NE}$ as $\Delta \mathrm{E}$ increases (Fig. $7 A$ ). With increasing postconceptional age [145 days (birth), Fig. $7 B]$, all $\Delta \mathrm{RVR}$ responses are negative but the higher levels of $\Delta N E$ are again associated with decreasingly negative $\Delta R V R$ as $\Delta E$ increases, whereas lower values of $\Delta \mathrm{NE}$ are associated with progressively decreasing predicted $\Delta \mathrm{RVR}$ as $\Delta \mathrm{E}$ increases, but the slope of the fall of predicted $\Delta \mathrm{RVR}$ with decreasing $\Delta \mathrm{E}$ at low levels of $\Delta \mathrm{NE}$ is more at 145 days postconceptional relative to 125 days postconceptional age. By the time the oldest postconceptional ages are reached (165 days postconceptional age, Fig. $7 C$ ), the entire contour shifts downward on the $\triangle R V R$ scale, but the basic contour pattern remains the same.

\section{DISCUSSION}

Hypoxemia is associated with adaptive circulatory responses to maintain systemic oxygen delivery to vital organs (38). Many of these responses vary according to developmental age $(9,22$, $23)$. The role that circulating vasoactive mediators play in these hemodynamic adaptations to hypoxemia are poorly understood. The present study attempts to examine the relationships of vasoactive mediators to the hemodynamic responses to hypoxemia in the developing lamb by the technique of response surface regression analysis (26). This analysis not oniy allows evaluation of the relationship of individual vaso a . e mediators with the hemodynamic variable, but also analyzes simple interactions between mediators in relation to the hemodynamic response. The use of this technique allows the construction of a model for these responses over the entire early development period of the lamb. These mathematical constructs derive their usefulness by demonstrating the trends of the relationships of the variables with developmental age. One may note that the extremes of the ranges of $\triangle \mathrm{MAP}$ and $\triangle \mathrm{RVR}$ reach physiologically impossible values. This is due to attempts to control the independent variables not being directly considered during the analysis by arbitrarily placing them at zero instead of some unknown critical value.

Herein, hypoxemia was associated with increased circulating levels of E, NE, and AVP in both fetal and neonatal lambs, as has been reported in previous studies $(10,11,40)$. Of these potential vasoactive mediators, the present study suggests $E$ as the main effector. In support of these findings, previous studies in adult experimental animals have noted strong correlations between systemic hemodynamic changes and increased levels of plasma catecholamines during hypoxemia and/or hypercapnia $(24,41-43)$. Further evidence for an essential role of the adrenergic system in these responses in the fetus is provided by Hyman et al. (44). Asphyxiation of anesthetized lamb fetuses by cord occlusion was associated with hypertension and bradycardia (44). After adrenergic blockade with phenoxybenzamine and propranolol, asphyxia was associated with profound hypotension and/or death. These results suggest that catecholamine release in response to asphyxia may be important to sustain circulatory homeostasis in the fetal lamb, as has been suggested for asphyxiated human newborn infants (16). Furthermore, $\alpha$-adrenergic blockade in normoxemic $(45-48)$ and hypoxemic $(47,49)$ fetuses was associated with decreased blood pressure, whereas chemical sympathectomy with 6-hydroxy-dopamine in chronically catheterized fetal lambs failed to block the elevation of blood pressure in response to cord-compression-induced hypoxemia (11). These findings suggest that circulating catecholamines rather than sympathetic nerve terminals modulate this response in the fetus.

In the current study, the predicted arterial pressure response to a given $\mathrm{E}$ response $(\Delta \mathrm{E})$ during hypoxemia was age dependent. Furthermore, NE and E responses appeared to have opposing relationships with arterial pressure responses in the developmental period studied. Age-dependent responses to catecholamines have been previously reported $(48,50,51)$. For example, arterial pressure responses to equivalent doses of tyramine, an agent that liberates NE from labile pool in nerves and chromaffin tissue, are progressively greater from fetal to neonatal to adult sheep (50). Woods et al. (48) demonstrated that near-term fetal lambs had significantly lower pressor response to a given dose of $\mathrm{NE}$ and lesser hypotensive response to isoproterenol than neonatal lambs. In addition, $E$ infusion elevated the blood pressure at all doses in piglets less than 1 wk old, but lowered the blood pressure in piglets older than 1 wk of age (51). Direct comparisons of these studies with results of the current study are not possible due to the complex nature of the responses to hypoxemia. However, the age-dependent arterial pressure responses of piglets to epinephrine infusion have a pattern which is similar to the arterial pressure versus $\mathrm{E}$ versus postconceptional age response to hypoxemia in lambs of the current study. Buckley et al. (51) have speculated that the age-dependent arterial pressure response to $\mathrm{E}$ infusion in piglets is due to age-related maturation of vascular $\beta$-adrenergic (vasodilatory) mechanisms which is asynchronous with vascular $\alpha$-adrenergic (vasoconstrictor) effector mechanism maturation. Data from the current study are compatible with such a hypothesis.

Renal vascular resistance responses to hypoxemia in fetal and neonatal sheep also fit well the response surface regression model of the measured variables in the current study. Here again, $E$ was the most strongly correlated of the measured variables in relation to the renal vascular response to hypoxemia. The increase in RVR in response to hypoxemia in fetuses of the current study was greater than that in neonates. Previous work (12) has also suggested age-related renal vascular responsiveness in that the renal vasculature of young fetuses appear to be more sensitive to catecholamines during hypoxemia than that of older fetuses. Similarly, increased renal vascular sensitivity to $E$ has been noted in neonatal relative to adult dogs (52).

In conclusion, this study of chronically catheterized fetal and newborn lambs demonstrated that normocapnic hypoxemia induced significant increases in serum concentrations of $E, N E$, and AVP in both fetal and neonatal lambs. A response surface regression model of the entire late fetal and neonatal developmental period revealed that $E$ responses were significantly correlated with responses of MAP and RVR. The relationships of MAP and RVR responses to that of $E$ and $N E$, and their interactions, were highly influenced by postconceptional age. These results suggest age-related maturation of vascular adrener- 
gic effector mechanisms that occur throughout the entire late fetal and neonatal life of the lamb.

\section{REFERENCES}

1. Volpe JJ 1976 Perinatal hypoxic-ischemic brain injury. Pediatr Clin North Am 23.383-397

2. Court DJ, Parer JT, Block BSB, Llanos AJ 1984 Effects of beta-adrenergic blockade on blood flow distribution during hypoxemia in fetal sheep. $J$ Dev Physiol 6:349-358

3. Sidi D, Kuipers JRG, Teitel D, Heymann MA, Rudolph AM 1983 Developmental changes in oxygenation and circulatory responses to hypoxemia in lambs. Am J Physiol 245:H674-682

4. Assali NS, Holm LW, Sehgal N 1962 Hemodynamic changes in fetal lamb in utero in response to asphyxia, hypoxia, and hypercapnia. Circ Res 11:423430

5. Brinkman CR, Weston P, Kirschbaum TH, Assali NS 1970 Effects of maternal hypoxia on fetal cardiovascular hemodynamics. Am J Obstet Gynecol 108:288-301

6. Cohn HE, Sacks EJ, Heymann MA, Rudolph AM 1974 Cardiovascular responses to hypoxemia and acidemia in fetal lambs. Am J Obstet Gynecol 120:817-824

7. Peeters LLH, Sheldon RE, Jones MD, Makowski EL, Meschia G 1979 Blood flow to fetal organs as a function of arterial oxygen content. Am J Obstet Gynecol 135:637-646

8. Anand SK, Northway JD, Crussi FG 1978 Acute renal failure in newborn infants. J Pediatr 92:985-988

9. Weismann DN, Clarke WR 1981 Postnatal age-related renal responses to hypoxemia in lambs. Circ Res 49:1332-1338

10. Comline RS, Silver M 1961 The release of adrenaline and noradrenaline from the adrenal glands in the fetal sheep. J Physiol 156:424-444

11. Lewis AB, Evans WN, Sischo W 1982 Plasma catecholamine responses to hypoxemia in fetal lambs. Biol Neonate 41:115-122

12. Robillard JE, Weitzman RE, Burmeister L, Smith FG Jr 1981 Developmental aspects of the renal response to hypoxemia in the lamb fetus. Circ Res 48:128-138

13. Cohen WR, Piasecki GJ, Jackson BT 1982 Plasma catecholamine during hypoxemia in fetal lamb. Am J Physiol 243:R520-R525

14. Nakai T, Yamada R 1978 The secretion of catecholamines in newborn babies with special reference to fetal distress. J Perinatol Med 6:39-45

15. Weismann DN, Herrig JE, McWeeny OJ, Ayres NA, Robillard JE 1983 Renal and adrenal responses to hypoxemia during angiotensin-converting enzyme inhibition in lambs. Circ Res 52:179-187

16. Lagercrantz H, Bistoletti P 1973 Catecholamine release in the newborn infant at birth. Pediatr Res 11:889-893

17. Alexander DP, Forsling ML, Martin MJ, Nixon DA, Ratcliffe JG, Redstone D, Tunbridge D 1972 The effect of maternal hypoxia on fetal pituitary hormone release in the sheep. Biol Neonate 21:219-228

18. Daniel SS, Husain MK, Milliez J, Stark RI, Yeh MN, James LS 1978 Renal response of fetal lamb to complete occlusion of umbilical cord. Am J Obstet Gynecol 131:514-519

19. Rurak DW 1978 Plasma vasopressin levels during hypoxemia and the cardiovascular effects of exogenous vasopressin in foetal and adult sheep. J Physiol (Lond) 277:341-357

20. Stark RI, Daniel SS, Husain KM, James LS, Wiele RLV 1979 Arginine vasopressin during gestation and parturition in sheep fetus. Biol Neonate 35:235-241

21. Weismann DN, Williamson HE 1981 Hypoxemia increases renin secretion rate in anesthetized newborn lambs. Life Sci 18:1887-1893

22. Weismann DN 1982 Tissue oxygen delivery in lambs: effect of postnatal age and acute hypoxemia. Biol Neonate 42:15-21

23. Robillard JE, Weismann DN, Ayres NA, Gomez RA, Nakamura KT 1984 Effects of hypoxemia on renal function during maturation. In Brodehl J, Ehrich JHH (eds) Pediatric Nephrology. Proceeding of the Sixth International Symposium of Pediatric Nephrology, Hannover, West Germany, 1983. Springer-Verlag, New York, pp 51-55

24. O'Brodovich HM, Stalcup SA, Pang LM, Mellins RB 1982 Hemodynamic and vasoactive mediator response to experimental respiratory failure. J Appl Physiol 52:1230-1236

25. Busija DW 1984 Interaction between hemorrhagic hypotension and hypoxia in regulation of renal vascular resistance in unanesthetized rabbits. Circ Shock 13:353-359

26. Myers RH 1976 Response Surface Methodology. Virginia Polytechnic Institute and State University, Blacksburg, VA

27. SAS Institute, Inc. 1982 SAS User's Guide: Statistics, SAS Institute, Inc., Cary, NC, pp 91-99

28. Jennings JJ , Crowley JP 1982 The influence of mating management on fertility in ewes following progesterone PMS treatment. Vet Rec 90:495-498

29. Gresham EL, Rankin JHG, Makowski EL, Meschia G, Battaglia FC 1972 An evaluation of fetal renal function in a chronic sheep preparation. $J$ Clin Invest 51:149-156

30. Robillard JE, Matson JR, Sessions C, Smith FG, Jr 1979 Developmenta aspects of renal tubular reabsorption of water in the lamb fetus. Pediatr Res 13:1172-1176

31. Robillard JE, Weitzman RE 1980 Developmental aspects of the fetal renal response to exogenous arinine vasopressin. Am J Physiol 238-F407-F414

32. Makowski EL, Meschia G, Droegemuller W, Battaglia FC 1968 Measurement of umbilical arterial blood flow to the sheep placenta and fetus in utero. Circ Res 23:623-630

33. Heymann MA, Payne BD, Hoffman JIE, Rudolph AM 1977 Blood flow measurements with radionuclide-labeled particles. Cardiovasc Dis 20:55-79

34. Haber E, Koerner T, Page LB, Kliman B, Purnode AJ 1969 Application of radioimmunoassay for angiotensin-I to the physiologic measurements of plasma renin activity in normal human subjects. J Clin Endocrinol 29:13491354

35. Oparil S 1975 Radioassay for Evaluation of the Renin-Angiotensin-Aldosterone System. G.D. Searle, New York, pp 1-50

36. Skowsky WR, Rosenbloom A, Fisher DA 1974 Radioimmunoassay of arginine vasopressin. J Clin Endocrinol Metab 38:278-288

37. Peuler JD, Johnson GA 1977 Simultaneous single isotope radioenzymatic assay of plasma norepinephrine, epinephrine, and dopamine. Life Sci 21:625-636

38. Steel RGD, Torrie JH 1960 Principles and Procedures of Statistics. McGrawHill, New York, pp 183-190

39. Heistad DD, Abboud FM 1980 Circulatory adjustments to hypoxia. Circulation 61:463-470

40. Jones CT, Robinson RO 1975 Plasma catecholamines in foetal and adult sheep. J Physiol 248:15-33

41. Rose Ce Jr, Althaus JA, Kaiser DL, Miller ED, Carey RM 1983 Acute hypoxia and hypercapnia: increase in plasma catecholamines in conscious dogs. Am J Physiol 245:H924-H929

42. Rose CE Jr, Anderson RJ, Carey RM 1984 Antidiuresis and vasopressin release with hypoxemia and hypercapnia in conscious dogs. Am J Physiol 247:R127-R134

43. O'Gradovich HM, Stalcup SA, Pang LM, Mellins RB 1982 Hem odynamic and vasoactive mediator response to experimental respiratory failur: J Appl Physiol 52:1230-1236
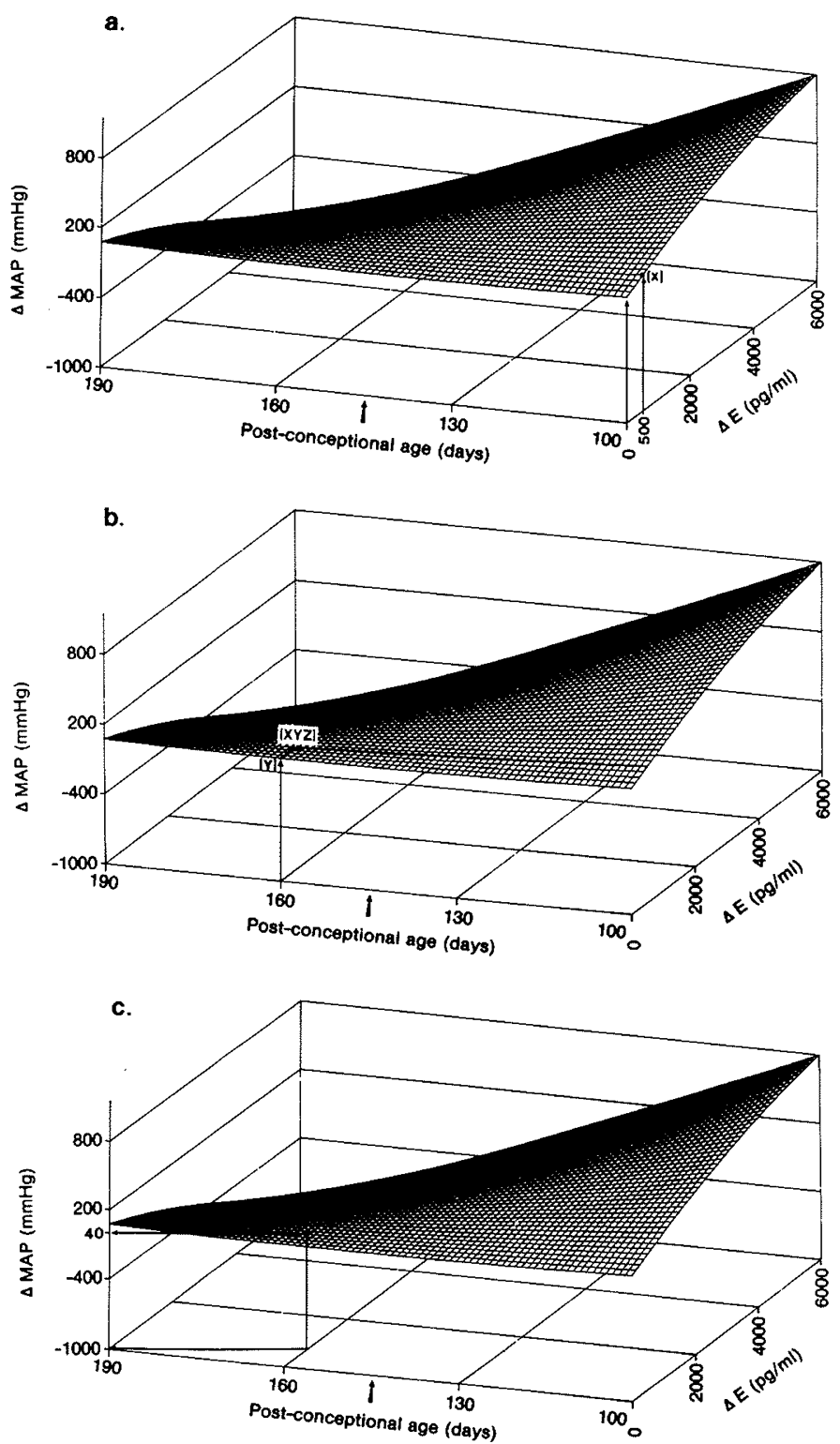
44. Hyman AI, Haworth G, Bowe ET, Daniel SS, James LS 1972 Effects of sympathetic blockade on the fetal responses to asphyxia. Biol Neonate 21:18

45. Edelstone DI, Merick RE, Caritis SN, Mueller-Heubach E 1980 Umbilical venous blood flow and its distribution before and during autonomic blockade in fetal lambs. Am J Obstet Gynecol 138:703-707

46. Vaparavouri EK, Shinebourne EA, Williams RL, Heymann MA, Rudolph AM 1973 Development of cardiovascular responses to autonomic blockade in intact fetal and neonatal lambs. Biol Neonate 22:177-188

47. Lewis AB, Donovan M, Platzker ACG 1980 Cardiovascular responses to autonomic blockade in hypoxemic fetal lambs. Biol Neonate 37.233-242

48. Woods JR Jr, Dandavino A, Murayama K, Brinkman CR III, Assali NS 1977 Autonomic control of cardiovascular functions during neonatal development and in adult sheep. Circ Res 40:401-407

49. Reuss ML, Parer JT, Harris JL, Krueger TR 1982 Hemodynamic effects of alpha-adrenergic blockade during hypoxia in fetal sheep. Am J Obstet Gynecol 142:4.10-415

50. Tabsh K, Huwayhid B, Murad S, Ushioda E, Erkkola R, Brinkman CR III, Assali NS 1982 Circulatory effects of chemical sympathectomy in fetal, neonatal, and adult sheep. Am J Physiol 243:H113-H122

51. Buckley NM, Gootman PM, Yellin EL, Brazeau P 1979 Age-related cardiovascular effects of catecholamine in anesthetized piglets. Circ Res 45:282292

52. Jose PA, Slotkoff LM, Lilienfield LS, Calcagno PL, Eisner GM 1974 Sensitivity of neonatal renal vasculature to epinephrine. Am J Physiol 226:796-799

\section{APPENDIX}

The technique for plotting individual points on a three-dimensional response surface contour graph is illustrated below by plotting $\Delta \mathrm{E} 500 \mathrm{pg} / \mathrm{dl}$ at a postconceptional age of 160 days to determine the predicted $\triangle \mathrm{MAP}$. The heavy arrow in Appendix Figure $1 a$ at postconceptional age 145 days signifies birth.

As shown in Appendix Figure $1 a, \Delta \mathrm{E} 500 \mathrm{pg} / \mathrm{dl}$ is first located on the $\Delta \mathrm{E}(\mathrm{X})$ axis. The point $(\mathrm{X})$ is transposed to the response surface contour by moving the point upward in parallel with the $\triangle \mathrm{MAP}(\mathrm{Z})$ axis plane, illustrated by the arrows to the transposed 0 and $500 \mathrm{pg} / \mathrm{dl}$ points in Appendix Figure $1 a$.

As shown in Appendix Figure $1 b$, postconceptional age of 160 days is then located on the $Y$ scale. This point $(Y)$ is then transposed to the response surface contour by moving the point upward in parallel with the $\triangle \mathrm{MAP}(\mathrm{Z})$ axis plane, as illustrated by the arrow to point $\mathrm{Y}$ in Appendix Figure $1 b$. The intersection of the contour lines from point $X(\Delta E)$ and $Y$ (postconceptional age), respectively, is illustrated as point $(X, Y, Z)$ in Appendix Figure $1 b$

As illustrated in Appendix Figure 1c, the length of the vector (black line) drawn in parallel to the $\triangle \mathrm{MAP}(\mathrm{Z})$ axis from point $(X, Y, Z)$ to the $(X, Y)$ plane, when transposed to the $\triangle$ MAP scale, indicates the predicted $\triangle \mathrm{MAP}$ relative to these two variables. This vector is transposed to the $\triangle \mathrm{MAP}(\mathrm{Z})$ scale as indicated by the arrows. Thus, the predicted $\triangle \mathrm{MAP}$ associated with $\Delta \mathrm{E} 500 \mathrm{pg} / \mathrm{ml}$ at 160 days postconceptional age is $40 \mathrm{~mm} \mathrm{Hg}$ on this response surface contour plot.

\section{Announcement}

\section{Symposium}

An International Symposium on Clinical, Biochemical, and Molecular Aspects of Fatty Acid Oxidation will be held at the Penn Tower Hotel, Philadelphia, PA, from November 6-9, 1988. Co-organizers of the Symposium are Kay Tanaka, M.D. and Paul M. Coates, Ph.D.

For information regarding registration and submission of abstracts, please contact: Paul M. Coates, Ph.D., Division of Genetics, Children's Hospital of Philadelphia, 34th and Civic Center Blvd., Philadelphia, PA 19104.

Deadline for registration and abstracts is June 1, 1988. Registration is limited to 200 participants. 